\title{
MICROPROPAGAÇÃO DE PORTA-ENXERTOS HÍBRIDOS DE Vitis labrusca X Vitis rotundifolia COM RESISTÊNCIA À PÉROLA-DA-TERRA (Eurhizococcus brasiliensis HEMPEL, HEMIPTERA: MARGARODIDAE) ${ }^{1}$
}

\author{
REGINA BEATRIZ BERND², ANA PAULA TRIVILIN ${ }^{3}$, UMBERTO ALMEIDA CAMARGO ${ }^{4}$, \\ ANA BEATRIZ COSTA CZERMAINSKI ${ }^{5}$.
}

RESUMO - A produção homogênea de porta-enxertos resistentes à pérola-da-terra (Eurhizococcus brasiliensis Hempel, Hemiptera: Margarodidae) e adaptados à região vitivinícola do Sul do País, pela técnica de micropropagação, poderá vir a atender à demanda do setor produtivo de uva e evitar as perdas causadas pela praga. O objetivo deste trabalho foi desenvolver um protocolo de micropropagação dos híbridos 1 e 2, que possuem as qualidades genéticas e de vigor desejadas para porta-enxerto, e resistência à pérola-da-terra. A partir de gemas axilares cultivadas em meio Galzy adicionado de $3 \mu \mathrm{M}$ de bezilaminopurina (BAP), foi possível induzir a multibrotação, com um número satisfatório de brotos, passível de ser incrementado por subcultivos sucessivos no mesmo meio de cultura. Os brotos obtidos neste meio e transferidos para o meio de cultura Galzy, adicionado de $8 \mu \mathrm{M} .10^{-3}$ de ácido naftalenoacético (ANA), enraizaram em 100\%, superando a dificuldade de enraizamento que em geral tem sido a maior barreira apresentada pela espécie $V$. rotundifolia e seus híbridos.

Termos para indexação: Cultivo in vitro, videira, uvas muscadíneas.

\section{MICRO PROPAGATION OF HYBRIDS OF VITIS LABRUSCA X VITIS ROTUNDIFOLIA ROOTSTOCKS WITH RESISTANCE TO PEROLA-DA-TERRA (EURHIZOCOCCUS BRASILIENSIS HEMPEL, HEMIPTERA: MARGARODIDAE).}

\begin{abstract}
The homogeneous production of rootstock resistant to perola-da-terra (Eurhizococcus brasiliensis Hempel, Hemiptera: Margarodidae) and well adapted to the growth conditions of the main grape growing region of Southern Brazil by the use of the micropropagation technique, may come to solve the demand of the grape productive sector and avoid losses caused by this pest. The objective of this work was to develop a protocol of micro propagation for the hybrids 1 and 2, which have the desired genetic qualities and vigor to be used as rootstock resistant to perola-da-terra. From axillaries buds cultivated in Galzy culture medium with $3 \mu \mathrm{M}$ of BAP, it was possible to induce multiple shooting with a reasonable number of shoots, which may be improved by successive subcultures in the same medium. The shoots were transferred to Galzy culture medium with $8 \mu \mathrm{M} .10^{-3}$ of NAA and all of them rooted, overcoming the rooting step that has been pointed out as the main barrier for micro propagation of the species Viits rotundifolia and its hybrids.
\end{abstract}

Index terms: Cultivo in vitro, grapevine, rootstocks, muscadine grape.

\section{INTRODUÇÃO}

A vitivinicultura na região Sul do Brasil, com uma área de produção de 35.263 hectares de vinhedos (Mello, 2005), tem sido ameaçada nos últimos anos por uma praga de solo nativa conhecida como pérola-da-terra (Eurhizococcus brasiliensis Hempel, Hemiptera: Margarodidae), que causa um declínio gradual na vitalidade da planta, seguida da morte da videira. Pela fácil dispersão, tanto em partículas de solo retidas em sapatos, enxadas e implementos agrícolas, como em mudas enraizadas e associada às formigas-doceiras, esta praga tende a se tornar um problema nacional (Botton et al., 2000). O controle químico não tem atuado com eficiência pela particularidade biológica de sobrevivência da praga, em forma de cistos, no solo (Soria \& Braghini, 1999), e a resistência genética do porta-enxerto tem sido indicada como um dos métodos mais promissores para o seu controle. Em testes de resistência feitos em condições de campo, Soria et al. (1993) verificaram que videiras da seção Muscadinia, espécie Vitis rotundifolia, mostraram-se resistentes à pérola-da-terra, sobrevivendo e produzindo em áreas com alta infestação. Essa espécie e híbridos dela derivados apresentam resistência também à filoxera, nematóides vetores virais, entre outros fitopatógenos (Olmo, 1986; Soria et al., 1994; Torregrosa \& Lopez, 1996; Kellow et al., 2002).

Devido a essas vantagens fitogenéticas da espécie, ela tem sido incorporada nos programas de melhoramento da videira

(Trabalho 167-06). Recebido em: 30-10-2006. Aceito para publicação em: 09-05-2007.

Bióloga, Dra ${ }^{a}$, Pesquisadora, Embrapa Tabuleiros Costeiros, Av. Beira Mar 3250, Caixa Postal 44, CEP 49025-040, Aracajú-SE. Fone: (79) 4009 1332. E-mail: regina@cpatc.embrapa.br.

Bióloga, pós-graduanda, UFRGS/Agronomia, Depto. Fitossanidade, Av. Bento Gonçalves 7712, CEP 91540-000, Porto Alegre-RS. Fone: (51) 3316 7417. E-mail: anatrivilin@yahoo.com.br.

${ }^{4}$ Eng $^{\text {o }}$ Agr $^{\circ}$, M.Sc., Pesquisador, Embrapa Uva e Vinho, Rua Livramento 515, Caixa Postal 130, CEP 95700-000, Bento Gonçalves-RS, Fone: (54) 3455 8037. E-mail: umberto@cnpuv.embrapa.br.

Eng ${ }^{a}$ Agr $^{\mathrm{a}}$, Dr ${ }^{\mathrm{a}}$, Pesquisadora, Embrapa Uva e Vinho, Rua Livramento 515, Caixa Postal 130, CEP 95700-000, Bento Gonçalves-RS, Fone: (54) 3455 8000. E-mail: ana@cnpuv.embrapa.br. 
(Torregrosa \& Lopez, 1996). Existe, porém, uma incompatibilidade genética da espécie $V$. rotundifolia $(2 \mathrm{n}=40)$ para uso como portaenxerto das variedades comerciais de videira $(2 n=38)$ e, para solucionar esse problema, são desenvolvidos híbridos interespecíficos (Torregrosa \& Bouquet, 1995). O Programa de Melhoramento Genético da Videira da Embrapa Uva e Vinho vem desenvolvendo híbridos interespecíficos de $V$. rotundifolia que apresentam resistência à pérola-da-terra e compatibilidade para enxertia com espécies comerciais de videira. Neste trabalho, foram utilizados dois desses híbridos, que chamaremos de híbrido $1 \mathrm{e}$ híbrido 2 para proteção das cultivares, resultantes do cruzamento de 'Isabel' ( $V$. labrusca) e 'Magnólia' ( $V$. rotundifolia), que apresentaram resistência em campo naturalmente infectado com pérola-da-terra por um período de seis anos, mantendo o vigor e a sanidade. A utilização de $V$. labrusca cv. Isabel como um dos genitores deu-se por sua adaptação às regiões vitivinícolas do Sul do Brasil, onde é geralmente plantada de pé-franco, além de apresentar resistência a alguns fitopatógenos de solo, como Fusarium oxysporum (Grigoletti Junior, 1985).

A dificuldade para estabelecimento de híbridos de $V$. rotundifolia como porta-enxerto reside na propagação pelo método tradicional de estaquia, no qual estacas lignificadas das variedades e híbridos de $V$. rotundifolia não enraízam, mesmo se submetidas a tratamento com auxinas exógenas (Goode Junior et al., 1982; Botelho et al., 2005), constituindo-se, assim, uma grande barreira para a produção de mudas em larga escala, necessária para abastecer o setor vitivinícola.

Desde a década de 80, a técnica de micropropagação in vitro tem sido uma alternativa utilizada para superar as dificuldades de propagação desta espécie, mas foi somente a partir de 1990 que foi obtido o enraizamento in vitro (Lee \& Wetzstein, 1990). Poucos são os trabalhos de micropropagação de $V$. rotundifolia e híbridos encontrados na literatura e, de uma maneira geral, quase todos os trabalhos apontam, como melhor meio de cultura para a produção de brotos, o meio MS (Murashige \& Skoog, 1962), completo (Lee \& Wetzstein, 1990; Gray \& Benton, 1991; Nasr El-Din et al., 1997), pela metade (Torregrosa \& Bouquet, 1995; Torregrosa \& Lopez, 1996), ou modificado (Sudasorno \& Goldy, 1991), exceto por um trabalho que indica o meio DSD1 (Borghezan et al., 2003). Nos trabalhos citados, o regulador vegetal BAP apresentou os melhores resultados na produção de brotos, em concentrações variáveis e específicas para cada variedade ou híbrido em estudo. Para micropropagação de cada genótipo de $V$. rotundifolia, variedade ou híbrido, é necessária a otimização da concentração de BAP (Gray \& Benton, 1991; Nasr El-Din et al., 1997; Torregrosa \& Bouquet, 1995). Os primeiros trabalhos de micropropagação de $V$. rotundifolia utilizavam dosagens altas de BAP (20mM e 40mM), mas foi observado que essas concentrações maiores são letais (com 65\% e 71\% de mortalidade, respectivamente, na variedade Summit) (Lee \& Wetzstein, 1990).

Este trabalho teve como objetivo desenvolver uma metodologia de micropropagação dos híbridos 1 e 2 em meio de cultura Galzy (Galzy, 1964), com obtenção de plântulas enraizadas dos dois híbridos, bem como testar a influência de diferentes tipos de recipientes (tubos de ensaio, placas de Petri e frascos de vidro) na indução de multibrotação do híbrido 1 . O protocolo desenvolvido poderá servir para produção em massa de portaenxertos resistentes à pérola-da-terra, permitindo suprir o mercado vitivinícola com grandes quantidades de material homogêneo, contribuindo para minimizar os efeitos causados pela praga na região Sul do Brasil.

\section{MATERIAL E MÉTODOS}

As plantas-matrizes dos híbridos 1 e 2 de $V$. labrusca $\mathrm{x}$. rotundifolia foram selecionadas pelo Programa de Melhoramento na Embrapa Uva e Vinho, em Bento Gonçalves-RS. Ramos herbáceos contendo cinco gemas axilares foram coletados no campo e, após a remoção das folhas, foram lavados em água corrente. As gemas axilares foram individualizadas em pedaços de ramo de aproximadamente 3 a 5 centímetros e imersas por 20 minutos em solução de hipoclorito de sódio a $1 \%(\mathrm{p} / \mathrm{v})$, Tween $80\left(2\right.$ gotas. $\left.\mathrm{L}^{-1}\right)$. O material foi lavado 3 vezes em água destilada estéril sob condições assépticas, em câmara de fluxo laminar. Após a desinfecção superficial, os segmentos caulinares contendo as gemas foram reduzidos de tamanho, restando $1 \mathrm{~mm}$ acima e $1 \mathrm{~cm}$ abaixo da gema axilar. As gemas foram então cultivadas em tubos de ensaio (110 $\mathrm{mm} \times 23 \mathrm{~mm}$ ) contendo $10 \mathrm{~mL}$ de meio Galzy (1964) com 8,05mM.10-3 ANA, 3\% de sacarose e $0,8 \%$ de ágar, pH 6,4 (ajustado antes da autoclavagem a $1 \mathrm{~atm}$ e $121^{\circ} \mathrm{C}$ por 20 minutos). O cultivo deu-se em sala de cultura a $26 \pm$ $2^{\circ} \mathrm{C}$ com fotoperíodo de 16 horas de luz (43ìmol fótons $\mathrm{m}^{-2} \mathrm{~s}^{-1}$ ), até o desenvolvimento de plântulas com um número considerável de gemas para a instalação do experimento.

Os explantes iniciais consistiram de uma gema e uma folha retirados dessas plântulas, e foram submetidos aos tratamentos: T1 (meio de cultura Galzy; 3ìM de BAP); $\mathrm{T}_{2}$ (meio de cultura Galzy; 5iM de BAP); $\mathrm{T}_{3}$ (meio de cultura Galzy; 10iM de BAP); T ${ }_{4}$ (meio de cultura MS; 5iM de BAP), contendo 3\% de sacarose e $0,8 \%$ de ágar, pH 6,4, ajustado antes da autoclavagem a $1 \mathrm{~atm}$ e $121^{\circ} \mathrm{C}$, por 20 minutos.

Vinte e cinco explantes do híbrido 1 foram inoculados em cada um dos diferentes tipos de recipientes, tubos de ensaio (110 mm x $23 \mathrm{~mm})$, placas de Petri $(100 \mathrm{~mm} \times 20 \mathrm{~mm})$ e frascos de vidro (120 mm x $55 \mathrm{~mm}$ ) no tratamento T1, e 15 explantes foram inoculados em tubos de ensaio ( $110 \mathrm{~mm} \times 23 \mathrm{~mm}$ ) em cada um dos tratamentos $\mathrm{T} 2, \mathrm{~T} 3 \mathrm{e} \mathrm{T} 4$, mantidos a $26 \pm 2{ }^{\circ} \mathrm{C}$ com fotoperíodo de 16 horas de luz (43ìmol fótons $\mathrm{m}^{-2} \mathrm{~s}^{-1}$ ), sendo transferidos para meio fresco a cada 30 dias. Os tubos de ensaio continham 1 explante, as placas de Petri e os frascos de vidro continham 5 explantes cada, conforme pode ser visto na Figura 1. Com o híbrido 2, foram inoculados 15 explantes individualizados em tubos de ensaio (110 $\mathrm{mm}$ x $23 \mathrm{~mm}$ ), em cada um dos tratamentos T1, T2 e T3, mantidos sob as mesmas condições de cultivo e intervalos de subcultivo supracitados.

Folhas e calos foram sistematicamente removidos dos explantes a cada repicagem. Após 120 dias em cultura, todos os brotos foram individualizados e transferidos para meio de enraizamento (Galzy acrescido de $8,05 \mathrm{mM} .10^{-3}$ de ANA, 3\% de sacarose e $0,8 \%$ de ágar, $\mathrm{pH} 6,4$ ), em tubos de ensaio ( $110 \mathrm{~mm} \times 23$ $\mathrm{mm})$. O enraizamento foi observado para identificar a influência 
do meio inicial na taxa de enraizamento.

Os experimentos, para cada híbrido testado, foram repetidos duas vezes, e as freqüências de multibrotação foram analisadas estatisticamente por meio de análise de variância, seguida do teste de Tukey, ao nível de significância de 5\% $(\mathrm{p}<0,05)$, para a identificação do tratamento mais eficiente.

\section{RESULTADOS E DISCUSSÃO}

As primeiras multibrotações foram visualizadas 40 dias após a introdução dos explantes nos meios de cultura. Após o período de 60 dias em cultura, todos os explantes de ambos os híbridos estavam produzindo multibrotações. Lee \& Wetzstein (1990) definem este estágio inicial de 8 semanas como o período de estabelecimento da cultura, onde a proliferação de brotos a partir de gemas axilares de $V$. rotundifolia é geralmente lenta. Após esse período, os brotos passaram então a se desenvolver mais rapidamente.

Aos 120 dias em cultura, ambos os híbridos haviam formado inúmeros brotos (Figura 2), que foram individualizados e transferidos para meio de enraizamento, Galzy com ANA. O número de brotos foi contabilizado, e a média do número de brotos produzidos por explante pode ser observada na Tabela 1 .

O híbrido 1 apresentou maior número de brotos no meio Galzy (T1 a T3) e, independentemente da concentração do regulador de crescimento $\mathrm{BAP}$, o número de brotos produzidos foi superior ao obtido no meio MS (T4), que é recomendado por muitos autores.

Os tratamentos T1 e T2 induziram um maior número de brotos em ambos os híbridos, não apresentando diferença significativa entre os dois tratamentos (Tabela 1). Dentre os três tratamentos com meio Galzy (T1 a T3), o tratamento T1 (3ì de BAP ) apresentou um maior número de brotações acima de 10 mm (dados não-publicados).

A média de brotos produzidos por explante foi bastante satisfatória para o período que permaneceu em cultura, e, segundo Torregrosa \& Bouquet (1995), a tendência é que se produzam ainda mais brotos a partir de multibrotações sucessivas, a partir de gemas diferenciadas em plântulas enraizadas.

O número de brotos produzidos pelo híbrido 1, no tratamento T1 (meio de cultura Galzy; 3ìM de BAP), não apresentou diferença significativa quando cultivado em placas de Petri, tubos de ensaio e frascos de vidro. Já Torregrosa \& Bouquet (1995), quando testaram a micropropagação de híbridos de $V$. rotundifolia em diferentes recipientes, observaram que a troca para Erlenmeyers de $250 \mathrm{~mL}$ mostrou-se ineficiente (não houve aumento do número de nós nem altura da parte aérea), mas o uso de placas de Petri, com $40 \mathrm{~mL}$ de meio, proporcionou ao explante maior contato com o meio e favoreceu a proliferação de brotos.

Comparando-se as médias do número de brotos produzidos em resposta ao meio de cultura (Tabela 1), houve diferença significativa entre os híbridos 1 e 2, segundo a análise de variância $(\mathrm{p}<0,05)$. Esse dado confirma os relatados por Torregrosa \& Bouquet (1995), em que híbridos de $V$. vinifera $\mathrm{x} V$. rotundifolia apresentavam grande variabilidade nas habilidades de crescimento e enraizamento em resposta ao meio de cultura, e alguns apresentavam-se mais adaptados à micropropagação. Essa sensibilidade do genótipo na interação com o meio de cultura poderá influenciar na escolha do híbrido que melhor se propaga in vitro para ser utilizado como porta-enxerto para abastecer o setor vitivinícola, que vem perdendo espaço com a dispersão da pérola-da-terra.

Os maiores números de brotos foram obtidos em meio Galzy (T1 a T3); porém, em meio MS (T4), houve melhor desenvolvimento da parte aérea, com caule levemente mais grosso e vigoroso, que resultou em melhor enraizamento, com raízes mais grossas e mais ramificadas, conforme pode ser visto na Figura 3.

A competência para o enraizamento de $V$. rotundifolia e híbridos é muitas vezes adquirida na etapa precedente, de multibrotação. Torregrosa \& Bouquet (1995), em estudo com diferentes híbridos de $V$. rotundifolia, observaram que a dosagem de 4,4mM de BAP, que apresentou os melhores índices de multibrotação em meio $\mathrm{MS} / 2$, reduziu em $70 \%$ o posterior enraizamento, quando comparada à concentração de 1,1mM BAP, sendo o enraizamento completamente inibido na concentração de 8,8mM de BAP. Para Lee \& Wetzstein (1990), com $V$. rotundifolia cv. Summit, a redução da concentração de BAP de $10 \mu \mathrm{M}$, em meio MS completo, onde obtiveram o maior número de brotos após 16 semanas em cultivo, para $5 \mathrm{mM}$ de BAP, proporcionou melhor enraizamento, com raízes maiores e mais ramificadas.

Muitos autores obtiveram enraizamento em meio de cultura sem a adição de reguladores vegetais quando a etapa precedente de produção e elongação de brotos foi satisfatória, mas a adição de auxinas variadas, em geral, promoveu o aumento da porcentagem de enraizamento, que não atingiu $100 \%$ nos trabalhos encontrados na literatura com uvas muscadíneas (Lee \& Wetzstein, 1990; Gray \& Benton, 1991; Torregrosa \& Lopez, 1996; Nasr El-Din et al., 1997). Em nosso trabalho, a dosagem de $10 \mathrm{mM}$ de BAP no meio indutor de multibrotação (Galzy), que para alguns autores impediu ou reduziu o enraizamento, não apresentou o efeito inibidor. A pequena dosagem de ANA $\left(8,05.10^{-}\right.$ ${ }^{3} \mathrm{mM}$.), adicionada ao meio Galzy, foi suficiente para induzir o enraizamento em todas as plântulas, provenientes de todos os tratamentos, de ambos os híbridos, sem a indução de calogênese, em um período de 30 dias.

TABELA 1 - Número médio de brotos produzidos por explante (Média \pm E.P.) dos híbridos 1 e 2 durante o período de 120 dias em cada tratamento. Bento GonçalvesRS, 2006.

\begin{tabular}{|c|c|c|}
\hline \multirow{2}{*}{ Tratamento } & Híbrido 1 & Híbrido 2 \\
\hline & Média \pm E.P. & Média \pm E.P. \\
\hline T1 (Galzy; 3нM BAP) & $4,9 \pm 0,6 \mathrm{a}^{1}$ & $6,5 \pm 0,8 \mathrm{a}$ \\
\hline T2 (Galzy; $5 \mu \mathrm{M}$ BAP) & $3,5 \pm 0,6 \mathrm{a}$ & $6,7 \pm 0,6 \mathrm{a}$ \\
\hline T3 (Galzy; $10 \mu \mathrm{M}$ BAP) & $2,7 \pm 0,4 b$ & $2,7 \pm 0,4 b$ \\
\hline T4 (MS; 5 $\mu \mathrm{M}$ BAP) & $1,9 \pm 0,4 \mathrm{c}$ & - \\
\hline
\end{tabular}

${ }^{1}$ Teste de Tukey: letras diferentes na mesma coluna designam diferença significativa entre tratamentos, com $\mathrm{p}<0,05$. 

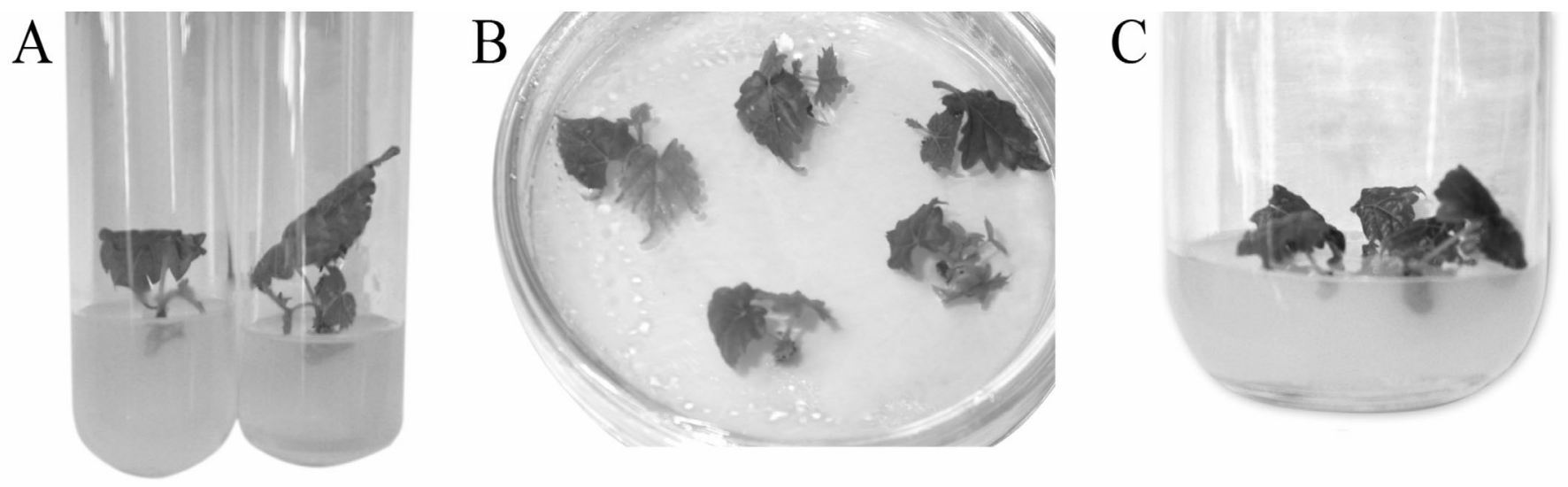

FIGURA 1 - Explantes iniciais da micropropagação do híbrido 1 em diferentes recipientes: "A" tubos de ensaio; "B” placas de Petri, e "C" frascos de vidro. Bento Gonçalves-RS, 2006.
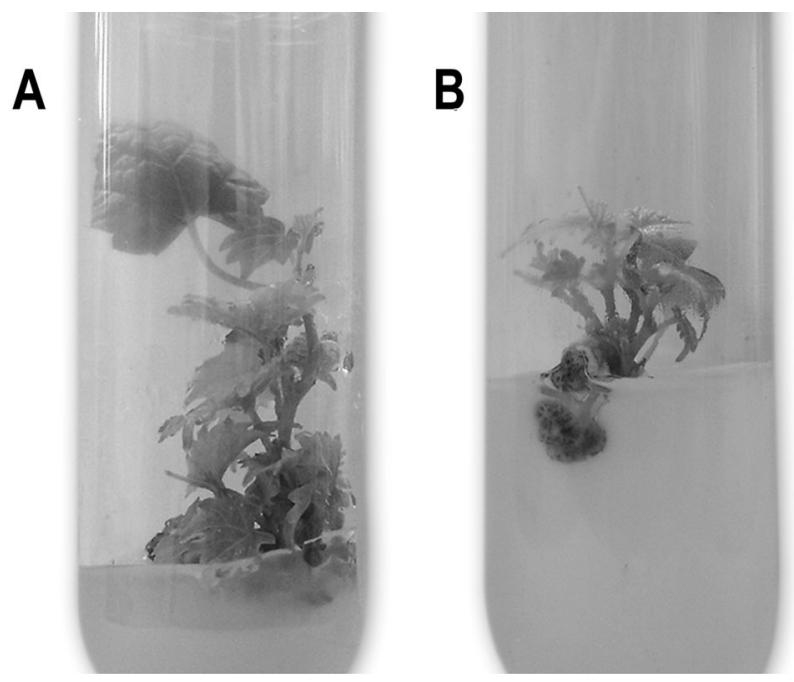

FIGURA 2 - Multibrotações após 120 dias de cultivo em tratamento T1 (Galzy com 3ì de BAP): "A" multibrotações do híbrido 1, e "B" multibrotações do híbrido 2. Bento Gonçalves-RS, 2006.

\section{CONCLUSÃO}

O protocolo mais eficiente para micropropagação in vitro dos híbridos estudados consiste em uma primeira etapa de 120 dias em meio Galzy (T1) para indução de multibrotação, com subcultivos em meio fresco a cada 30 dias, podendo estes serem repetidos mais algumas vezes, sempre intercalados pelo subcultivo em meio MS (T4), para aprimorar o desenvolvimento da parte aérea das brotações antes da individualização dos brotos e, por fim, o enraizamento em meio Galzy com $8,05 \cdot 10^{-3} \mathrm{mM}$ de ANA.
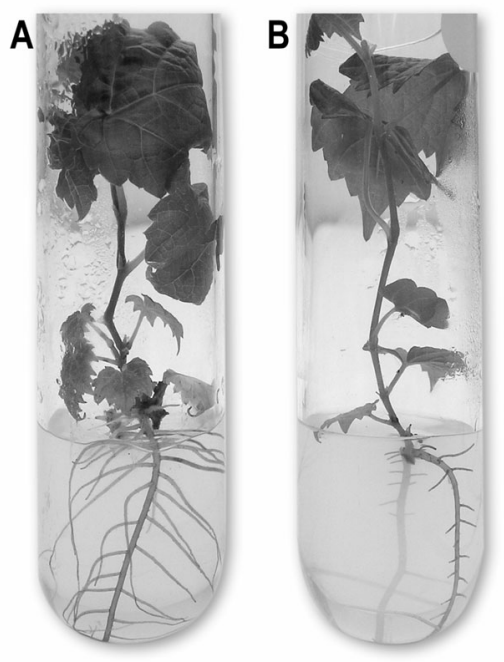

FIGURA 3 - Plântulas do híbrido 1 com 30 dias em meio de enraizamento (Galzy, 8,05.10-3 $\mu \mathrm{M}$ ANA), desenvolvidas a partir de brotos individualizados aos 120 dias de cultivo em: "A": tratamento T4 (meio de cultura MS; 5ìM de BAP), e B: tratamento $\mathrm{T}_{2}$ (meio de cultura Galzy; 5ì de BAP).

\section{AGRADECIMENTOS}

Ao Conselho Nacional de Pesquisa - CNPq, pela concessão da bolsa de Iniciação Tecnológica Industrial (ITI) a Ana Paula Trivilin; às estagiárias da Empresa Brasileira de Pesquisa Agropecuária - EMBRAPA, Renata dal Magro e Valéria Aquino Canterle, pelo preparo dos meios de cultura, a Marcela B. Leão de Souza, pelas fotografias e a Rodrigo Nicolini, pela edição das figuras. 


\section{REFERÊNCIAS}

BORGHEZAN, M.; MORAES, L. K. A. de; MOREIRA, F. M.; SILVA, A. L. da. Propagação in vitro e avaliação de parâmetros morfofisiológicos de porta-enxertos de videira. Pesquisa Agropecuária Brasileira, Brasília, v.38, n.8, p.783789, 2003.

BOTELHO, R. V.; MAIA, A. J.; PIRES, E. J. P.; TERRA, M. M.; SCHUCK, E. Efeitos de reguladores vegetais na propagação vegetativa do porta-enxerto de videira '43-43' (Vitis vinifera x $V$. rotundifolia). Revista Brasileira de Fruticultura, Jaboticabal, v.27, n.1, p.6-8, 2005.

BOTTON, M.; HICKEL, E. R.; SORIA, S. J.; TEIXEIRA, I. Bioecologia e controle da pérola-da-terra Eurhizococcus brasiliensis (Hempel, 1922) (Hemiptera: Margarodidae) na cultura da videira. Bento Gonçalves: Embrapa-CNPUV, 2000. 23 p. (Circular Técnica, 27).

GALZY, R. Technique de thermothérapie des viroses de la vigne. Annales des Épiphyties, Paris, v.15, n.3, p.245-256, 1964.

GOODE JUNIOR, D. K.; KREWER, G. W.; LANE, R. P.; DANIEL, J. W. Rooting studies of dormant muscadine grape cuttings. HortScience, Alexandria, v.17, n.4, p.644-645, 1982.

GRAY, D. J.; BENTON, C. M. In vitro micropropagation and plant establishment of muscadine grape cultivars (Vitis rotundifolia). Plant Cell, Tissue and Organ Culture, Dordrecht, v.27, n.1, p.7-14, 1991.

GRIGOLETTI JUNIOR, A. Fusariose da videira: caracterização, variabilidade do Fusarium oxysporum f. sp. herbemontis e fontes de resistência em Vitis spp. 1985. 76f. Tese (Doutorado em Fitopatologia) - Universidade Federal de Viçosa, Viçosa, 1985.

KELLOW,A. V.; MCDONALD, G.; CORRIE,A. M.; HEESWIJCK, $\mathrm{R}$. van. In vitro assessment of grapevine resistance to two populations of phylloxera from Australian vineyards. Australian Journal of Grape and Wine Research, Adelaide, v.8, n.2, p.109-116, 2002.

LEE, N.; WETZSTEIN, H. Y. In vitro propagation of muscadine grape by axillary shoot proliferation. Journal of the American Society for Horticultural Science, Mount Vernon, v.115, n.2, p.324-329, 1990.

MELLO, L. M. R. de (Ed.). Cadastro vitícola do Rio Grande do Sul: 2001 a 2004. Bento Gonçalves: Embrapa Uva e Vinho, 2005. 1 CD-ROM.

MURASHIGE, T.; SKOOG, F. A revised medium for rapid growth and bioassays with tobacco tissue cultures. Physiologia Plantarum, Copenhagen, v.15, n.3, p.473-497, 1962.

NASR EL-DIN, T.; RIZK, I. A.; MADKOUR, M. In vitro propagation of muscadine grapes (Vitis rotundifolia). Bulletin of the Faculty of Agriculture, Cairo, v.48, n.1, p.129142, 1997.

OLMO, H.P. The potential role of (vinifera $\mathrm{x}$ rotundifolia) hybrids in grape variety improvement. Experientia, Basel, v.42, n.8, p.921-926, 1986.

SORIA, S. D. de J.; BRAGHINI, L. C. Controle químico da pérolada-terra Eurhizococcus brasiliensis (Hempel in Wille, 1922) (Homoptera: Margarodidae) 2. Avaliação da bioeficácia do vamidothion na cultura da videira. Entomologia y Vectores, Rio de Janeiro, v.6, n.5, p.555-561, 1999.

SORIA, S. de J.; CAMARGO, U. A.; FÃO, V. de M.; BRAGHINI, L. C. Avaliação no campo da resistência de videiras americanas à pérola-da-terra Eurhizococcus brasiliensis. In: CONGRESSO BRASILEIRO DE VITICULTURA E ENOLOGIA, 7., 1993, Bento Gonçalves/Garibaldi-RS. Anais... Bento Gonçalves: EMBRAPA-CNPUV, 1993. p.19-23.

SORIA, S. de J.; CAMARGO, U. A.; BRAGHINI, L. C. Obtenção de plantas de videiras enxertadas sobre híbridos de Euvitis $\mathrm{x}$ Muscadínea visando à avaliação da resistência à pérolada-terra. In: REUNIÃO TÉCNICA DE FRUTICULTURA, 3., 1994, Porto Alegre. Resumos... Porto Alegre: FEPAGRO, 1994. p. 61-62.

SUDARSONO, A.; GOLDY, R. G. Growth regulator and axillary bud position effects on in vitro establishment of Vitis rotundifolia. HortScience, Alexandria, v.26, n.3, p.304-307, 1991.

TORREGROSA, L.; BOUQUET A. In vitro propagation of Vitis $x$ Muscadinia hybrids by microcuttings or axillary budding. Vitis, Geneva, v.34, n.4, p.237-238, 1995.

TORREGROSA, L.; LOPEZ, G. Culture in vitro des hybrides Vitis x Muscadinia: Intérêt de la micropropagation axillaire par rapport au microboturage. Progrès Agricole et Viticole, Montpellier, v.113, n.8, p.176-181, 1996. 
Revista Brasileira de Fruticultura, vol 29, n. 2, p. 350-354.

FOLHA: Páginas 351, 352 e 353.

Onde se lê:

O símbolo "ì" em unidades de medida.

Leia-se:

O símbolo " $\mu$ ". 
O arquivo disponível sofreu correções conforme ERRATA publicada no Volume 29 Número 3 da revista. 